\title{
A retrospective analysis of mandibular fractures in Mewat, India
}

\author{
Vijay Laxmy Malhotra ${ }^{1}$, Amita Sharma ${ }^{1}$, Rajiv Tanwar ${ }^{1}$, Meenu Dhiman $^{1}$, Radhey Shyam² ${ }^{2}$, Depinder Kaur ${ }^{3}$ \\ ${ }^{1}$ Department of Dentistry, SHKM Government Medical College, Nalhar, Nuh, Mewat, \\ ${ }^{2}$ Department of Public Health Dentistry, Post Graduate Institute of Dental Sciences, Rohtak, \\ ${ }^{3}$ Department of Anaesthesia, SHKM Government Medical College, Nalhar, Nuh, Mewat, India
}

\begin{abstract}
J Korean Assoc Oral Maxillofac Surg 2021;47:365-372)
Objectives: Mandibular fractures vary significantly with respect to epidemiological and demographic parameters among populations. To date, no study has evaluated these aspects of mandibular fractures in Nuh, Mewat, Haryana, India. To retrospectively analyze the incidence, age and sex distributions, etiology, anatomic distribution, occlusal status, treatment modality provided, and their correlation in patients who suffered isolated mandibular fractures.

Materials and Methods: The records of maxillofacial injury patients who reported to the Department of Dentistry, SHKM Government Medical College from January 2013 to December 2019, were retrieved from our database, and necessary information was collected. The data collected were analyzed statistically using IBM SPSS ver. 21.

Results: Totals of 146 patients and 211 fractures were analyzed. There were 127 males and 19 females with an age range of 3-70 years (mean age, 26 years). Road traffic accident (RTA) was the most common cause of fracture (64.4\%), followed by fall (19.9\%), assault (15.1\%), and sports injury (0.7\%). Of all patients, $42.5 \%$ had bilateral fractures, $31.5 \%$ had left side fracture, $21.2 \%$ had right side fracture, $3.4 \%$ sustained midline symphyseal fracture, and $1.4 \%$ had symphyseal fracture along one side of the mandible. Site distribution was as follows: parasymphysis (34.6\%), angle (23.7\%), condyle (20.4\%), body (12.8\%), symphysis (4.3\%), ramus $2.4 \%$, and dentoalveolar $1.9 \%$. The most common facture combination was angle with parasymphysis $(17.8 \%)$. Occlusion was disrupted in $69.2 \%$ patients. Closed reduction was the predominant treatment modality.

Conclusion: The data obtained from retrospective analyses of maxillofacial trauma increase the understanding of variables and their outcomes among populations. The results of the present study are comparable to those of the literature in some aspects and different in others.
\end{abstract}

Key words: Mandibular fractures, Mewat India, Etiology, Retrospective study, Incidence

[paper submitted 2021. 2. 22 / revised 2021. 6. 12 / accepted 2021. 6. 17]

\section{Introduction}

The mouth is the gateway to the body. Trauma to this region affects the airway, food intake, speech, facial aesthetics, and overall psychosocial well-being of patients. Mandibular fractures comprise $15.5 \%-59 \%$ of all maxillofacial fractures ${ }^{1}$. The mandible is the second most often fractured adult facial bone because of its projecting and vulnerable position in the face $^{2}$.

\section{Vijay Laxmy Malhotra}

Department of Dentistry, SHKM Government Medical College, Nalhar, Nuh, Mewat 122107, India

TEL: +91-9958310059

E-mail: vijay_laxmy13@yahoo.co.in

ORCID: https://orcid.org/0000-0003-3119-7371

(c) This is an open-access article distributed under the terms of the Creative Commons Attribution Non-Commercial License (http://creativecommons.org/ licenses/by-nc/4.0/), which permits unrestricted non-commercial use, distribution, and reproduction in any medium, provided the original work is properly cited.

Copyright (C) 2021 The Korean Association of Oral and Maxillofacial Surgeons.
Various countries across the globe have provided statistics for mandibular fractures, and the information provided is unique to the countries of origin and their residents. Several variables are related to the study of mandibular fractures due to differences in demographic characteristics reported in the literature ${ }^{3}$. Socio-economic trends, geographic locations, and local behavior have a considerable impact on the etiology of the injury, which sequentially influences the distribution of fracture sites $^{4}$. No unanimity has been found for the common pattern of mandibular fractures because of disparate associated factors such as geographic area, population mass, socioeconomic status, regional government, status of the population studied, and political era ${ }^{5}$.

It is a paradox that, despite being adjacent to the information technology hub Gurugram and industrial hub Faridabad, Mewat (now renamed as Nuh) is the most underdeveloped district of not only Haryana state, but of all India. This region lies in the semi-arid zone and is inhabited primarily by Meo 
Muslims. According to the 2011 census, it has an estimated population of 10.89 lacs $(1 \mathrm{lac}=100,000)$ and an area of 1,507 $\mathrm{km}^{2}$. A majority of the population $(88 \%)$ resides in rural areas and is engaged in agriculture. Scarcity of water limits the industries in this region. This area lags significantly in various socio-economic parameters such as standard of living, education, health, sex, agriculture, livestock, and economy. The literacy rate is $69.94 \%$ among males and decreases to $37.6 \%$ in females. The available health data indicate a lack of good health care facilities ${ }^{6}$. Before establishment of the medical college, there were limited health care facilities for management of facial trauma. SHKM Government Medical College, located in the Nalhar village of Nuh, was established in 2012, and is the only tertiary care health facility there. The institution caters to various blocks of Mewat and adjoining areas, namely, Firozpur Zirka, Taoru and Punhana, as well as adjoining districts of Haryana, Rajasthan, and Uttar Pradesh.

This retrospective study aimed to analyze mandibular fractures for incidence, age and sex distribution, etiology, anatomic distribution, occlusal status, and treatment provided and their correlation in patients who visited the Department of Dentistry, SHKM Government Medical College, Nalhar, Nuh, Haryana, from January 2013 to December 2019.

\section{Materials and Methods}

The records of maxillofacial injury patients who reported to the Department of Dentistry, SHKM Government Medical College, from January 2013 to December 2019, were retrieved from the participating institution's database. A retrospective analysis was conducted on the records of patients having isolated mandibular fractures. The data collected included age, sex, address, etiology of trauma, anatomic location, side of fracture, occlusion status, and treatment provided. Patients with associated maxillofacial fractures

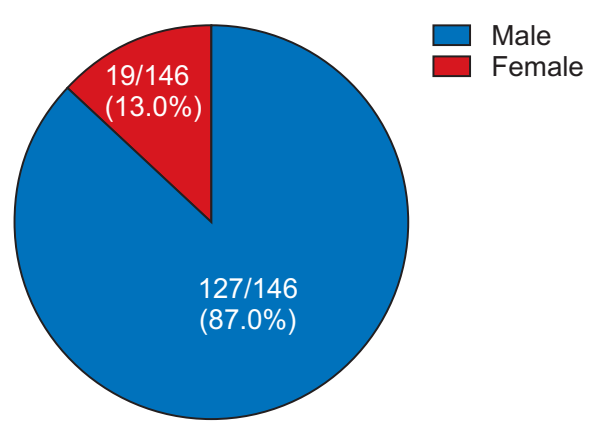

Fig. 1. Sex distribution of mandibular fractures. Vijay Laxmy Malhotra et al: A retrospective analysis of mandibular fractures in Mewat, India. J Korean Assoc Oral Maxillofac Surg 2021 and/or comminuted mandibular fractures and patients whose records were incomplete or missing were excluded from the study. The data collected were analyzed statistically using IBM SPSS Statistics software (ver. 21.0; IBM, Armonk, NY, USA).

\section{Results}

\section{Age and sex}

A total of 146 patients with 211 fractures was analyzed. There were 127 males (87.0\%) and 19 females (13.0\%) at a ratio of 7:1.(Fig. 1) The age of the patients ranged from 3 to 70 years, and the mean age was 26 years.

Patients were divided into six groups by age as groupI: 0-10 years, group-II: 11-20 years, group-III: 21-30 years, group-IV: $31-40$ years, group-V: 41-50 years, and groupVI: $>50$ years.(Table 1) The highest prevalence of trauma was seen in age group-III $(60 / 146,41.1 \%)$, followed by age group-II (44/146, 30.1\%). Minimum prevalence was seen in age group-VI (4/146, 2.7\%). Among males, the maximum number of cases of mandibular fracture was seen in age group-III followed by age group-II; in females, age groupsIII, IV, and V were involved equally.

\section{Etiology}

In this study, road traffic accidents (RTAs) were the pre-

Table 1. Sex distribution among age groups

\begin{tabular}{ccccc}
\hline Age $(\mathrm{yr})$ & Age group & Male (n) & Female (n) & Total (n) \\
\hline $0-10$ & I & 6 & 3 & 9 \\
$11-20$ & II & 41 & 3 & 44 \\
$21-30$ & III & 56 & 4 & 60 \\
$31-40$ & IV & 13 & 4 & 17 \\
$41-50$ & V & 8 & 4 & 12 \\
$>50$ & VI & 3 & 1 & 4 \\
\hline
\end{tabular}

Vijay Laxmy Malhotra et al: A retrospective analysis of mandibular fractures in Mewat, India. J Korean Assoc Oral Maxillofac Surg 2021

Table 2. Relationship between etiology and sex

\begin{tabular}{lccc}
\hline \multirow{2}{*}{ Etiology } & \multicolumn{2}{c}{ Sex } & \multirow{2}{*}{ Total (n) } \\
\cline { 2 - 3 } & Male (n) & Female (n) & \\
\hline Road traffic accident & 82 & 12 & 94 \\
Assault & 19 & 3 & 22 \\
Fall & 25 & 4 & 29 \\
Sports injury & 1 & 0 & 1 \\
Industrial injury & 0 & 0 & 0 \\
Other & 0 & 0 & 0 \\
\hline
\end{tabular}

Vijay Laxmy Malhotra et al: A retrospective analysis of mandibular fractures in Mewat, India. J Korean Assoc Oral Maxillofac Surg 2021 
dominant cause of mandibular fractures $(94 / 146,64.4 \%)$. The second most common cause was fall (29/146, 19.9\%), followed by assault $(22 / 146,15.1 \%)$. There was only one case related to sports injury $(1 / 146,0.7 \%)$. No case of mandibular fracture was seen as a result of industrial trauma.(Table 2)

RTAs were most common in age group-III (43/96, 44.8\%), followed by age group-II (29/94, 30.2\%). Fall as an etiology was mainly seen in age group-II $(13 / 29,44.8 \%)$, followed by age group-III $(7 / 29,24.1 \%)$. The only case of sports injury was in age group-I.(Fig. 2)

RTAs were the predominant cause of mandibular fractures in both males and females (males: 82/127, 64.6\%; females: $12 / 19,63.2 \%$ ), followed by fall (males: $25 / 127,19.7 \%$, females: $4 / 19,21.1 \%$ ) and assault (males: 19/127, 15.0\%; females: $3 / 19 ; 15.8 \%)$. There was no variation in etiology based on sex. The only case of sports injury occurred in males.(Table 2)

\section{Anatomical distribution}

The present study found that $62 / 146(42.5 \%)$ of patients had bilateral fractures, and 46/146 (31.5\%) of patients had left side fracture. The right side of the mandible was involved in 31/146 (21.2\%) patients. In 5/146 (3.4\%) of patients, midline symphyseal fractures were seen alone, while in $2 / 146$ (1.4\%) patients, midline symphyseal fractures were seen with involvement of either side of the mandible. The left side of the mandible was the more commonly involved side among both males and females. Bilateral fractures were more common than single fractures among males.(Fig. 3)

Of 211 fractures, parasymphysis fractures were observed

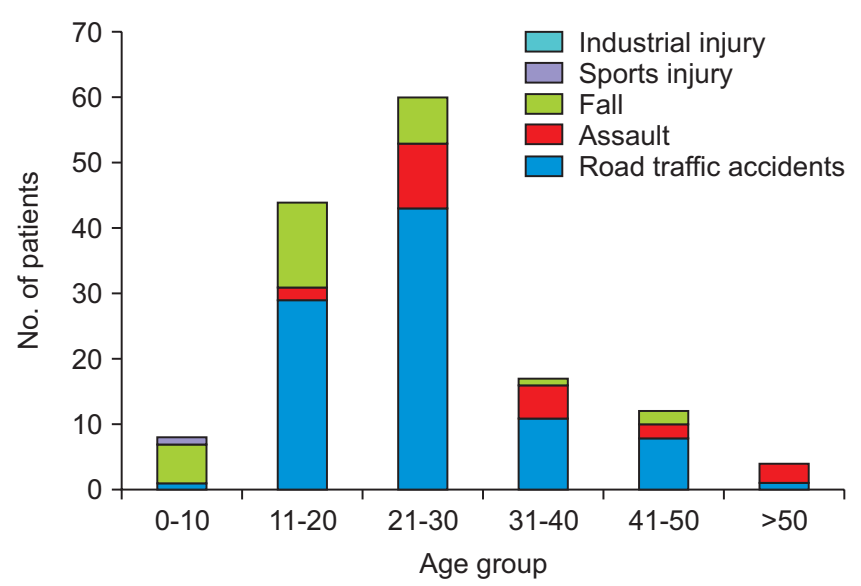

Fig. 2. Distribution of etiological factors in different age groups. Vijay Laxmy Malhotra et al: A retrospective analysis of mandibular fractures in Mewat, India. J Korean Assoc Oral Maxillofac Surg 2021 at $73 / 211(34.6 \%)$ sites and was the predominant site in this study, followed by angle 50/211 (23.7\%), condyle $43 / 211$ (20.4\%), body $27 / 211$ (12.8\%), symphysis $9 / 211$ (4.3\%), and ramus $5 / 211(2.4 \%)$. The least common fracture site was dentoalveolar, observed at $4 / 211$ sites $(1.9 \%)$. No coronoid fracture was observed in the present study.(Table 3 )

The most common combination pattern of fractures observed was angle with parasymphysis $26 / 146(17.8 \%)$, followed by parasymphysis with condyle 16/146 (11.0\%) and body with angle $4 / 146$ (2.7\%). The least common combinations were angle with dentoalveolar $(0.7 \%)$, angle with condyle $(0.7 \%)$, symphysis $(0.7 \%)$, and body with angle and condyle $(0.7 \%)$.(Table 4$)$

In cases of single mandibular fractures among males, parasymphysis was the most common site $(24 / 127,18.9 \%)$, while in females, parasymphysis and condyle $(3 / 19,15.8 \%)$ were involved equally. Among combination fractures, angle and parasymphysis was the most common combination in both males $(20 / 127,15.7 \%)$ and females $(6 / 19,31.6 \%)$.(Table 4)

In age group-I, the most common single fracture was para-

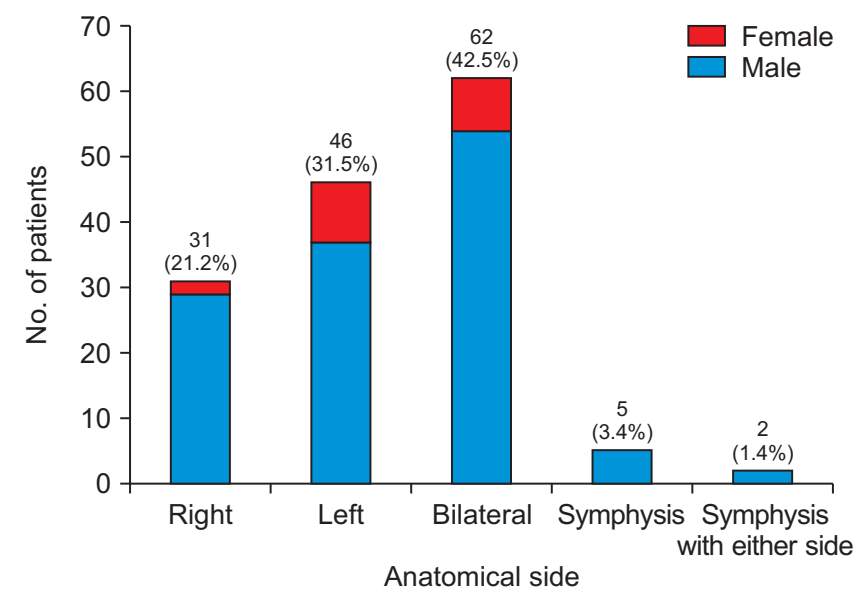

Fig. 3. Sex and anatomical side distribution of mandibular fractures $(n=146)$

Vijay Laxmy Malhotra et al: A retrospective analysis of mandibular fractures in Mewat, India. J Korean Assoc Oral Maxillofac Surg 2021

Table 3. Anatomical site distribution of mandibular fractures $(\mathrm{n}=211)$

\begin{tabular}{lc}
\hline Fracture site & $\mathrm{n}(\%)$ \\
\hline Parasymphysis & $73(34.6)$ \\
Angle & $50(23.7)$ \\
Condyle & $43(20.4)$ \\
Body & $27(12.8)$ \\
Symphysis & $9(4.3)$ \\
Ramus & $5(2.4)$ \\
Dentoalveolar & $4(1.9)$ \\
\hline
\end{tabular}

Vijay Laxmy Malhotra et al: A retrospective analysis of mandibular fractures in Mewat, India. J Korean Assoc Oral Maxillofac Surg 2021 
Table 4. Relationship of fracture site to sex, age group, and occlusal status

\begin{tabular}{|c|c|c|c|c|c|c|c|c|c|c|c|}
\hline \multirow[b]{2}{*}{ Fracture site } & \multirow[b]{2}{*}{$\begin{array}{c}\text { Total } \\
(n=146)\end{array}$} & \multicolumn{2}{|c|}{ Sex distribution } & \multicolumn{6}{|c|}{ Age group } & \multicolumn{2}{|c|}{ Occlusal status } \\
\hline & & Male & Female & I & II & III & IV & V & VI & $\begin{array}{l}\text { Patient with } \\
\text { normal } \\
\text { occlusion }\end{array}$ & $\begin{array}{c}\text { Patient with } \\
\text { deranged } \\
\text { occlusion }\end{array}$ \\
\hline Dentoalveolar & 3 & 2 & 1 & 0 & 2 & 0 & 0 & 1 & 0 & 2 & 1 \\
\hline Symphysis & 5 & 5 & 0 & 0 & 1 & 2 & 2 & 0 & 0 & 5 & 0 \\
\hline Parasymphysis & 27 & 24 & 3 & 4 & 9 & 11 & 1 & 2 & 0 & 17 & 10 \\
\hline Body & 16 & 14 & 2 & 0 & 3 & 8 & 2 & 3 & 0 & 9 & 7 \\
\hline Angle & 14 & 12 & 2 & 0 & 3 & 6 & 2 & 2 & 1 & 5 & 9 \\
\hline Ramus & 1 & 1 & 0 & 0 & 1 & 0 & 0 & 0 & 0 & 1 & 0 \\
\hline Condyle & 18 & 15 & 3 & 2 & 7 & 4 & 3 & 1 & 1 & 4 & 14 \\
\hline Coronoid & 0 & 0 & 0 & 0 & 0 & 0 & 0 & 0 & 0 & 0 & 0 \\
\hline Angle+parasymphysis & 26 & 20 & 6 & 1 & 9 & 12 & 3 & 0 & 1 & 1 & 25 \\
\hline Body+condyle & 4 & 4 & 0 & 0 & 1 & 2 & 0 & 1 & 0 & 0 & 4 \\
\hline Body+angle & 5 & 5 & 0 & 1 & 1 & 3 & 0 & 0 & 0 & 0 & 5 \\
\hline Parasymphysis+condyle & 16 & 15 & 1 & 1 & 5 & 6 & 1 & 2 & 1 & 0 & 16 \\
\hline Angle+dentoalveolar & 1 & 1 & 0 & 0 & 0 & 1 & 0 & 0 & 0 & 0 & 1 \\
\hline Parasymphysis+angle+ramus & 2 & 2 & 0 & 0 & 1 & 1 & 0 & 0 & 0 & 0 & 2 \\
\hline Body+angle+condyle & 1 & 1 & 0 & 0 & 0 & 0 & 1 & 0 & 0 & 0 & 1 \\
\hline Symphysis+condyle & 3 & 3 & 0 & 0 & 1 & 1 & 1 & 0 & 0 & 0 & 3 \\
\hline Angle+condyle & 1 & 1 & 0 & 0 & 0 & 1 & 0 & 0 & 0 & 1 & 0 \\
\hline Body+symphysis & 1 & 1 & 0 & 0 & 0 & 1 & 0 & 0 & 0 & 0 & 1 \\
\hline Parasymphysis+ramus & 2 & 1 & 1 & 0 & 0 & 1 & 1 & 0 & 0 & 0 & 2 \\
\hline
\end{tabular}

Age group: group-I, 0-10 years; group-II, 11-20 years; group-III, 21-30 years; group-IV, 31-40 years; group-V, 41-50 years; group-VI, >50 years.

Values are presented as number only.

Vijay Laxmy Malhotra et al: A retrospective analysis of mandibular fractures in Mewat, India. J Korean Assoc Oral Maxillofac Surg 2021

symphysis, and there were no predominant combination fractures. In age group-II, the most common single fracture was parasymphysis, and the predominant combination fracture was parasymphysis with angle. In age group-III, the most common single fracture was parasymphysis, and the combination fracture was parasymphysis with angle. In age groupIV, the most common single fracture was condyle, and the combination fracture was parasymphysis with angle.(Table 4) In age group- $\mathrm{V}$, the most common single fracture was body, and the most common combination was parasymphysis with condyle. In age group-VI, there was no predominantly affected site or fracture.(Table 4)

\section{Occlusal status}

Occlusion was not disturbed in 45/146 (30.8\%) of the patients and was disturbed in 101/146 (69.2\%) of patients.(Fig. 4) In the present study, the most cases of disturbed occlusion were seen with a combination of angle with parasymphysis fractures (25/101), and fewest cases of deranged occlusion were evident in cases of ramal (0/101) fracture and symphyseal $(0 / 101)$ fracture.(Table 4$)$

Among single fractures, the most cases of deranged occlusion were seen in condylar fractures (14/18, 77.8\%). Among combination fractures, the highest percentage of disturbed occlusion was seen in parasymphysis and condylar fractures;

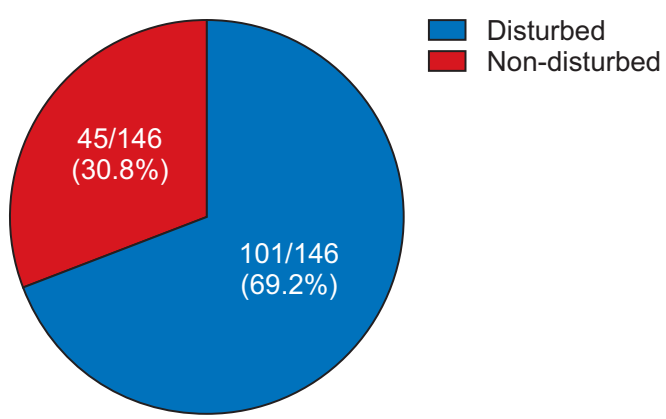

Fig. 4. Distribution of occlusion status.

Vijay Laxmy Malhotra et al: A retrospective analysis of mandibular fractures in Mewat, India. J Korean Assoc Oral Maxillofac Surg 2021

all 16 of 16 cases had disturbed occlusion, followed by angle and parasymphysis $(25 / 26,96.2 \%)$. The minimum percentage of disturbed occlusion was seen in symphysis $(0 \%)$ and ramal $(0 \%)$ fracture. Interestingly in the only case of angle and condyle fracture, occlusion was not disturbed.(Table 4)

\section{Treatment}

In the present study, closed reduction was performed in $139 / 146(95.2 \%)$ of patients and open reduction and internal fixation in 7/146 (4.8\%) of patients. In 114/146 (78.1\%) of patients, the Erich arch bar with maxillomandibular fixation (MMF) was performed; in 18/146 (12.3\%) patients, Ivy eyelet wiring was performed; and in 7/146 (4.8\%) patients, 
Table 5. Treatment modalities $(n=146)$

\begin{tabular}{lc}
\hline \multicolumn{1}{c}{ Mode of treatment } & $\mathrm{n}(\%)$ \\
\hline Closed reduction (Bridle wiring/wire splint) & $7(4.8)$ \\
Closed reduction (Ivy eyelet) & $18(12.3)$ \\
Closed reduction (Erich arch bar) & $114(78.1)$ \\
Open reduction & $7(4.8)$ \\
\hline
\end{tabular}

Vijay Laxmy Malhotra et al: A retrospective analysis of mandibular fractures in Mewat, India. J Korean Assoc Oral Maxillofac Surg 2021

bridle wiring/wire splinting was performed.(Table 5)

\section{Discussion}

The first description of mandibular fractures dates back to the 17th century B.C. in the "Edwin Smith Papyrus" bought by Smith in Luxor in 1862, and later translated by Breasted ${ }^{7}$. In his manuscript, "Hippocratic Collection," Hippocrates described manual reduction of mandibular fractures with monomaxillary dental fixation and bandaging ${ }^{8,9}$. The importance of the concept of occlusion in management of mandibular fractures was found in a textbook written in Salerno, Italy ${ }^{10}$. The concept of MMF was described by Guglielmo Salicetti in his book Cyrurgia $^{11}$ in 1492. This concept was reintroduced by Gilmer $^{12}$ in the United States, in 1887. Until the 1900s, the concept of closed reduction was the mainstay of treatment for mandibular fractures. As the concepts in anesthesia and asepsis improved, a new era of open reduction and internal fixation began. From Luhr's concept of compression plates to Spissel's AO/ASIF (Association for Osteosynthesis/Association for Study of Internal Fixation) and the latest concept of non-compression plates introduced by Michlete and colleagues ${ }^{13-16}$ and later refined by Champy et al. ${ }^{17}$, the treatment of mandibular fractures has been in a constant state of evolution.

The basis of evolution in management strategies can be attributed to a better understanding of the biomechanics of the mandible, its behavior in response to traumatic forces, fracture patterns, etiology, epidemiology, mode of healing, and functional rehabilitation ${ }^{18}$.

The mandible has varying strengths of bone in different regions, in correlation with stress distribution on function. It is a tubular V-shaped bone that articulates with the skull via paired temporomandibular joints ${ }^{19}$.

Mandibular fractures constitute a significant percentage of maxillofacial fractures ${ }^{1}$. In most studies, males are affected more commonly than females ${ }^{2,5,20}$. In an extensive study by Ellis et al. ${ }^{21}$, who analyzed over 3,400 mandibular fractures within 10 years between 1974-1983, there was a clear male preponderance.

This might be due to greater participation in outdoor activities and higher levels of physical activity in males. Furthermore, males are more likely to be involved in traffic accidents and altercations $\mathrm{s}^{22,23}$. Other reasons behind this sex pattern could be higher social activity, drug abuse, vehicular driving, industrial work, and sports issues among males ${ }^{24,25}$. In the present study males also outnumbered females at a ratio of $7: 1$. The sex ratio observed in other studies was $3: 1^{18}, 4: 1^{26,27}$, and $6.6: 1^{28}$. Mandibular fractures have been reported in all age groups (ranging from small children ${ }^{22}$ to individuals of 95 years $^{29}$ ). In the present study, the range was from three to 70 years with an mean of 26 years; the mean age reported in other studies was 39.5 years $^{26}, 31.5$ years $^{18}$, and 32.1 years $^{27}$.

A majority of patients belonged to age group-III (41.1\%) in the present study, similar to the 21- to 30-year-old group reported in other studies ${ }^{21,26,28}$. The incidence of fractures increased from age group-I to -III and then decreased from age group-III to -VI. Thus, the incidence of mandibular fracture is lowest at both age extremes in the present study, which is similar to other studies ${ }^{26}$. Among young persons, less frequent fracture likely is due to the percentage of time spent indoors and the elastic nature of young bone ${ }^{2}$. Among individuals older than 60 years, comparatively less exposure to the outside world and a less active life can explain the lower incidence of mandibular fractures ${ }^{20}$.

In a study by Shah et al. ${ }^{26}$, the peak age group for mandibular fractures was 21-30 years in both males and females. In the present study, group-III was the peak age group in makes, while females age groups-III, IV, and V were affected equally.

There is a striking contrast in the etiology of mandibular fractures in developed and developing countries. The most common causative factor in developing countries is RTAs $^{3,22,23,30}$. This might be due to rash driving, speeding, subpar roads, unwillingness to follow road safety measures such as wearing of helmets or seatbelts, inadequate implementation of traffic rules, drunken driving, increased use of vehicles by minors, poor maintenance of vehicles, etc et,20,22,23 $^{3}$.

In the present study, the most common cause of mandibular fractures was RTAs $(94 / 146,64.4 \%)$, followed by fall $(29 / 146,19.9 \%)$, assault $(22 / 146,15.1 \%)$, and sports $(1 / 146$, $0.7 \%)$. This finding is consistent with previous studies ${ }^{26,31-33}$. In India, the increasing incidence of alcohol dependence and drunken driving is the reason behind the increased incidence of fracture due to RTAs. Giri et al. ${ }^{34}$ noted that the high prevalence of intoxication among the affected population 
points to the growing necessity of reliably documented and scientifically backed evidence of road traffic legislation, with compulsory use of seat belts and safety helmet regulations.

The only case of a sports injury was reported in age groupI, the first decade of life. Fall was the most common cause of mandibular fracture (75\%) among the elderly (group-VI), likely because of medical conditions, poor muscular control and bodily response, and lack of support and care. Moreover, in geriatric patients, bones become more brittle and have a susceptibility to injury even after a minor fall $l^{35}$.

In the current study, the most common fracture site was the parasymphysis $(73 / 211,34.6 \%)$. This finding is similar to previous studies. This could be explained by the horseshoe shape of the mandible, resulting in fractures of the parasymphysis under forces due to the large canine roots and convex structure $^{18,20,29,32,36}$. In this study, the second most common unilateral fracture site was angle $(50 / 211,23.7 \%)$, followed by condyle $(43 / 211,20.4 \%)$.

Various studies have different results for anatomical distribution of mandible fractures. Brasileiro and Passeri ${ }^{37}$ reported the mandibular condyle as the most common site of fracture. Dongas and $\mathrm{Hall}^{38}$ and Morris et al. ${ }^{39}$ have shown mandibular angle to be the most common site of fracture, while Adi et $\mathrm{al}^{40}$ have shown the mandibular body as the most common site of fracture.

In most studies, the coronoid process of the mandible is the least affected site of mandibular fracture ${ }^{20,26,41}$. This is true for the present study, with no reported case of coronoid fracture.

The most common combination fracture found in the study was angle with parasymphysis $(26 / 146,17.8 \%)$, which is similar to information reported in other studies ${ }^{18,27,31,38,42}$. However, additional studies reported parasymphysis with condyle ${ }^{18,20,24}$ and body with angle as the most common combinations ${ }^{5,39}$.

Specific association between fracture locations is an important consideration when performing clinical assessment of a patient with a mandible fracture. Knowledge that one particular type of fracture is more likely with a fracture at another location can aid in diagnosis ${ }^{39}$. In the present study, the second most common combination was parasymphysis with condyle (16/146, 11.0\%).

The left side was involved more commonly than the right, at a ratio of 1.4:1. This was true for males and females. Among assault patients, the left side of the mandible was affected more commonly, as most of the Indian population is right-handed ${ }^{18}$. According to McManus ${ }^{43}$, Professor of Psychology at University College London, approximately $90 \%$ of humans are right-handed, explaining why the left side of the face is the most common location of injury.

It is important to manage mandibular fractures to establish stable occlusion, preserve normal mandibular arch form, restore mandibular functions, retain the symmetry of the face, and avoid advancement of developmental disorders. Treatments generally vary according to fracture type, number and location, surgeon performance, and patient characteristics (e.g., age, dental profile, choice of treatment, financial status). The various treatment options available are intermaxillary fixation, open reduction and internal fixation, closed treatment with external fixation, and treatment with Kirschner wire $^{26}$.

In the present study, closed reduction was the predominant management method (139/146, 95.2\%).

The Ivy eyelet method of intermaxillary fixation was used in patients with no or minimal displacement of fractured segments. In cases needing elastic traction to reduce displaced fracture segments, the Erich arch bar was used. Bridle wiring was performed in pediatric trauma patients. The mean period of intermaxillary fixation was four to six weeks. However, in delayed union, intermaxillary fixation was continued for up to eight weeks. The advantages of closed reduction include reduced morbidity as it does not traumatize the vascular envelope, lower expense, less invasiveness, need for less surgical experience, and can be carried out under local anesthesia with minimal equipment. The disadvantages include a significant period of immobilization and required prolonged closure of the oral cavity, to which the patient might not agree, and it requires intact dentition, maintenance of oral hygiene, and patient compliance. It cannot be utilized in certain situations such as underlying medical conditions and difficult occlusion. Moreover, once the intermaxillary fixation has been released, patients have difficulty in achieving full mouth opening for a few weeks, for which exercises and hot water fomentation are advised. Closed reduction was the preferred method in this study because of the location as a general dentistry department with limited faculty for advanced maxillofacial procedures and limited availability of general anesthesia. This indicates the need for a separate oral and maxillofacial surgical unit in each medical college. Moreover, most of the patients visiting the participating institute experienced financial limitations and preferred less expensive methods of treatment. 


\section{Conclusion}

Knowledge gained from the study of demographic and epidemiological factors of mandibular trauma will be helpful in the formation of clinical and research priorities for proper treatment and prevention of such injuries. Demographic evaluation of preventive measures helps reduce the incidence of trauma. Medical colleges in India, are tertiary health care centers and handle trauma cases in their emergency departments. Medical colleges in India have a provision only for a general department of dentistry, and there is no guideline for a separate oral and maxillofacial unit. The authors strongly recommend provision for a separate oral and maxillofacial surgical unit in each medical college.

\section{ORCID}

Vijay Laxmy Malhotra, https://orcid.org/0000-0003-3119-7371

Amita Sharma, https://orcid.org/0000-0002-4374-4259

Rajiv Tanwar, https://orcid.org/0000-0003-4699-578X

Meenu Dhiman, https://orcid.org/0000-0002-7012-272X

Radhey Shyam, https://orcid.org/0000-0001-5758-3540

Depinder Kaur, https://orcid.org/0000-0002-3562-0432

\section{Authors' Contributions}

V.L.M. and R.T. participated in data collection and wrote the manuscript. V.L.M., R.S., and M.D. participated in the study design and performed the statistical analysis. V.L.M., D.K., and A.S. participated in the study design and coordination and helped to draft the manuscript. All authors read and approved the final manuscript.

\section{Ethics Approval and Consent to Participate}

The study was approved by the Independent Ethics Committee (IEC) of SHKM Government Medical College (No. SHKM/IEC/2020/94). The study was a retrospective review and the informed consent was waived by the IEC.

\section{Conflict of Interest}

No potential conflict of interest relevant to this article was reported.

\section{References}

1. Zix JA, Schaller B, Lieger O, Saulacic N, Thorén H, Iizuka T. Incidence, aetiology and pattern of mandibular fractures in central Switzerland. Swiss Med Wkly 2011;141:w13207. https://doi. org/10.4414/smw.2011.13207

2. Boffano P, Kommers SC, Karagozoglu KH, Gallesio C, Forouzanfar T. Mandibular trauma: a two-centre study. Int J Oral Maxillofac Surg 2015;44:998-1004. https://doi.org/10.1016/ j.ijom.2015.02.022

3. Krishnaraj S, Chinnasamy R. A 4-year retrospective study of mandibular fractures in a South Indian city. J Craniofac Surg 2007;18: 776-80. https://doi.org/10.1097/scs.0b013e318069005d

4. van den Bergh B, van Es C, Forouzanfar T. Analysis of mandibular fractures. J Craniofac Surg 2011;22:1631-4. https://doi. org/10.1097/SCS.0b013e31822e5f20

5. Ogundare BO, Bonnick A, Bayley N. Pattern of mandibular fractures in an urban major trauma center. J Oral Maxillofac Surg 2003;61:713-8. https://doi.org/10.1053/joms.2003.50118

6. Mehta PK, Saxena N, Mangla B, Birla S, Hussain R, Sultan A, et al. Identifying backwardness of Mewat region in Haryana: a blocklevel analysis. Gurgaon: Sehgal Foundation; 2015.

7. Breasted JH. The Edwin Smith surgical papyrus. Facsimile and hieroglyphic transliteration with translation and commentary. Chicago (IL): University of Chicago Press; 1930.

8. Withington ET. Hippocrates: oeuvres completes. Cambridge (MA): Harvard University Press; 1928.

9. Gahhos F, Ariyan S. Facial fractures: hippocratic management. Head Neck Surg 1984;6:1007-13. https://doi.org/10.1002/ hed.2890060605

10. Brophy TW. Oral surgery: a treatise on the diseases, injuries and malformations of the mouth and associated parts. Philadelphia (PA): P. Blakiston's; 1915.

11. Prevost N. Translation of Salicetti's Cyrurgia. Lyons: [publisher unknown]; 1492.

12. Gilmer TL. A case of fracture of the lower jaw with remarks on treatment. Arch Dent 1887;4:388.

13. Luhr HG. [On the stable osteosynthesis in mandibular fractures]. Dtsch Zahnarztl Z 1968;23:754. German.

14. Spiessl B. New concepts in maxillofacial bone surgery. Berlin: Springer; 1976:21.

15. Spiessl B. Internal fixation of the mandible: a manual of AO/ASIF principles. Berlin: Springer; 1989.

16. Michelet FX, Deymes J, Dessus B. Osteosynthesis with miniaturized screwed plates in maxillo-facial surgery. J Maxillofac Surg 1973;1:79-84. https://doi.org/10.1016/s0301-0503(73)80017-7

17. Champy M, Loddé JP, Schmitt R, Jaeger JH, Muster D. Mandibular osteosynthesis by miniature screwed plates via a buccal approach. J Maxillofac Surg 1978;6:14-21. https://doi.org/10.1016/s03010503(78)80062-9

18. Srinivasan B, Balakrishna R, Sudarshan H, Veena GC, Prabhakar S. Retrospective analysis of 162 mandibular fractures: an institutional experience. Ann Maxillofac Surg 2019;9:124-8. https://doi. org/10.4103/ams.ams 3618

19. Busuito MJ, Smith DJ Jr, Robson MC. Mandibular fractures in an urban trauma center. J Trauma 1986;26:826-9. https://doi. org/10.1097/00005373-198609000-00008

20. Natu SS, Pradhan H, Gupta H, Alam S, Gupta S, Pradhan R, et al. An epidemiological study on pattern and incidence of mandibular fractures. Plast Surg Int 2012;2012:834364. https://doi. org/10.1155/2012/834364

21. Ellis E 3rd, Moos KF, el-Attar A. Ten years of mandibular fractures: an analysis of 2,137 cases. Oral Surg Oral Med Oral Pathol 1985;59:120-9. https://doi.org/10.1016/0030-4220(85)90002-7

22. Chrcanovic BR, Abreu MH, Freire-Maia B, Souza LN. 1,454 Mandibular fractures: a 3-year study in a hospital in Belo Hori- 
zonte, Brazil. J Craniomaxillofac Surg 2012;40:116-23. https://doi. org/10.1016/j.jcms.2011.03.012

23. Rangaswamy G, Kumar AS, Manjula G, Ramesh P. A retrospective study of epidemiology fractures of mandible in tertiary care teaching hospital over a period of a decade. J Evol Med Dent Sci 2016; 5:4011-6. https://doi.org/10.14260/jemds/2016/918

24. Ramadhan A, Gavelin P, Hirsch JM, Sand LP. A retrospective study of patients with mandibular fractures treated at a Swedish University Hospital 1999-2008. Ann Maxillofac Surg 2014;4:178-81. https://doi.org/10.4103/2231-0746.147119

25. Elgehani RA, Orafi MI. Incidence of mandibular fractures in Eastern part of Libya. Med Oral Patol Oral Cir Bucal 2009;14:e529-32. https://doi.org/10.4317/medoral.14.e529

26. Shah N, Patel S, Sood R, Mansuri Y, Gamit M, Rupawala T. Analysis of mandibular fractures: a 7-year retrospective study. Ann Maxillofac Surg 2019;9:349-54. https://doi.org/10.4103/ams. ams 2219

27. Oruç M, Işik VM, Kankaya Y, Gürsoy K, Sungur N, Aslan G, et al. Analysis of fractured mandible over two decades. J Craniofac Surg 2016;27:1457-61. https://doi.org/10.1097/SCS.0000000000002737

28. Rashid A, Eyeson J, Haider D, van Gijn D, Fan K. Incidence and patterns of mandibular fractures during a 5-year period in a London teaching hospital. Br J Oral Maxillofac Surg 2013;51:794-8. https://doi.org/10.1016/j.bjoms.2013.04.007

29. Lee KH. Epidemiology of mandibular fractures in a tertiary trauma centre. Emerg Med J 2008;25:565-8. https://doi.org/10.1136/ emj.2007.055236

30. Subhashraj K, Ramkumar S, Ravindran C. Pattern of mandibular fractures in Chennai, India. Br J Oral Maxillofac Surg 2008;46:126-7. https://doi.org/10.1016/j.bjoms.2006.10.004

31. Vyas A, Mazumdar U, Khan F, Mehra M, Parihar L, Purohit C. A study of mandibular fractures over a 5-year period of time: a retrospective study. Contemp Clin Dent 2014;5:452-5. https://doi. org/10.4103/0976-237X.142808

32. Barde D, Mudhol A, Madan R. Prevalence and pattern of mandibular fracture in Central India. Natl J Maxillofac Surg 2014;5:153-6. https://doi.org/10.4103/0975-5950.154818

33. Tejaswi SS, Subash TS. A clinical study of incidence, etiology, and pattern of mandibular fractures in K. R. Hospital, Mysore. Int J Prev Clin Dent Res 2018;5:50-2.

34. Giri KY, Singh AP, Dandriyal R, Indra N, Rastogi S, Mall SK, et al. Incidence and pattern of mandibular fractures in Rohilkhand region, Uttar Pradesh state, India: a retrospective study. J Oral Biol Craniofac Res 2015;5:140-5. https://doi.org/10.1016/ j.jobcr.2015.07.007

35. Manodh P, Prabhu Shankar D, Pradeep D, Santhosh R, Murugan A. Incidence and patterns of maxillofacial trauma-a retrospective analysis of 3611 patients-an update. Oral Maxillofac Surg 2016;20:37783. https://doi.org/10.1007/s10006-016-0576-z

36. Jung HW, Lee BS, Kwon YD, Choi BJ, Lee JW, Lee HW, et al. Retrospective clinical study of mandible fractures. J Korean Assoc Oral Maxillofac Surg 2014;40:21-6. https://doi.org/10.5125/jkaoms.2014.40.1.21

37. Brasileiro BF, Passeri LA. Epidemiological analysis of maxillofacial fractures in Brazil: a 5-year prospective study. Oral Surg Oral Med Oral Pathol Oral Radiol Endod 2006;102:28-34. https://doi. org/10.1016/j.tripleo.2005.07.023

38. Dongas P, Hall GM. Mandibular fracture patterns in Tasmania, Australia. Aust Dent J 2002;47:131-7. https://doi.org/10.1111/ j.1834-7819.2002.tb00316.x

39. Morris C, Bebeau NP, Brockhoff H, Tandon R, Tiwana P. Mandibular fractures: an analysis of the epidemiology and patterns of injury in 4,143 fractures. J Oral Maxillofac Surg 2015;73:951.e112. https://doi.org/10.1016/j.joms.2015.01.001

40. Adi M, Ogden GR, Chisholm DM. An analysis of mandibular fractures in Dundee, Scotland (1977 to 1985). Br J Oral Maxillofac Surg 1990;28:194-9. https://doi.org/10.1016/0266-4356(90)900883

41. Gadicherla S, Sasikumar P, Gill SS, Bhagania M, Kamath AT, Pentapati KC. Mandibular fractures and associated factors at a tertiary care hospital. Arch Trauma Res 2016;5:e30574. https://doi. org/10.5812/atr.30574

42. Patel N, Kim B, Zaid W. A detailed analysis of mandibular angle fractures: epidemiology, patterns, treatments, and outcomes. J Oral Maxillofac Surg 2016;74:1792-9. https://doi.org/10.1016/ j.joms.2016.05.002

43. McManus IC. The history and geography of human handedness. In: Sommer IEC, Kahn RS, eds. Language lateralization and psychosis. Cambridge: Cambridge University Press; 2009:37-58. https:// doi.org/10.1017/CBO9780511576744.004

How to cite this article: Malhotra VL, Sharma A, Tanwar R, Dhiman M, Shyam R, Kaur D. A retrospective analysis of mandibular fractures in Mewat, India. J Korean Assoc Oral Maxillofac Surg 2021;47:365-372. https://doi.org/10.5125/jkaoms.2021.47.5.365 